\title{
Effects of the group's knowledge of member satisfaction upon group performance'
}

Marvin E. Shaw and d. Michael Blum UNIVERSITY OF FLORIDA

\begin{abstract}
Five-person groups were run in each of three satisfaction feedback conditions: no feedback, overt feedback and covert feedback. In the overt condition all Ss publicly signalled their satisfaction to the group, whereas in the covert condition satisfaction was signalled anonymously. Performance was best in covert; next best in overt, and poorest in the no feedback condition. Results were interpreted in terms of validity of feedback.
\end{abstract}

\section{Problem}

It often is the case that a group accepts a decision that only a few members consider the best one, each dissatisfied member thinking that he alone is displeased with the decision. This "pluralistic ignorance" (Krech, Crutchfield and Ballachey, 1962) is assumed to interfere with effective group functioning. If so, increasing members' awareness of the feelings of others in the group should increase group effectiveness. This is especially true for difficult tasks which require the best efforts of all group members. Hence, knowledge of the satisfaction of group members may be relatively unimportant for easy tasks, but of great importance for difficult tasks.

The purpose of the present experiment, then, was to test the hypothesis that group effectiveness improves with increased knowledge of member satisfaction, and that this effect is greater on difficult than on easy tasks.

\section{Method}

Nine groups of five persons each (college undergraduates) were run in each of three satisfaction feedback conditions: no feedback, overt feedback, and covert feedback. Feedback was accomplished by means of a panel of 25 lights placed in the middle of an oval work table. Each $\mathrm{S}$ was provided with a silent, five-position switch, located under the table, which controlled five of the lights on the panel. Each S could signal his satisfaction to the group by setting his switch at the first position for low satisfaction, at the second position for somewhat higher satisfaction, and so on, with the fifth position indicating the greatest satisfaction. On the overt feedback condition, each $\mathrm{S}$ was assigned colored lights corresponding to his experimental "name," and his lights were placed in a single row. Thus group members could easily determine the indicated feelings

1 This research was supported by the Office of Naval Research, Contract NR $170-266$, Nonr - 580(11). of each member. In the covert condition, all lights were red and those assigned to each S were randomly distributed on the panel, so each S could signal his satisfaction anonymously. It was believed that the covert condition would result in more veridical feedback, since the inhibiting effects of being identified are not present.

Each group attempted to solve three problems. These problems had previously been scaled on six dimensions (Shaw, 1963), and were selected to have approximately the same scale values on Solution Multiplicity, Cooperation Requirements, Intellectual-Manipulative Requirements, Population Familiarity, and Intrinsic Interest, varying only on Difficulty. The first problem, a city ranking task similar to that used by Gaier and Bass (1955), has a Difficulty scale value of 2.50 . The second task was adapted from the change of work task formulated by Maier (1953), and has a Difficulty scale value of 4.19 . The third task was a puzzle problem concerning dormitory room assignments, given certain limiting conditions. Its Difficulty scale value is 6.09 . These tasks are described fully in a recent report (Shaw, 1963, Tasks 80, 23, and 97, respectively). Tasks were given to groups in different orders such that each task was attempted first, second, and third an equal number of times, matched across satisfaction feedback conditions.

Groups were allowed a maximum of 30 minutes on each task. At the end of the experimental session, each $\mathrm{S}$ completed a questionnaire designed to measure overall satisfaction.

\section{Results}

Since time to solve is the only performance score that is directly comparable across tasks, it is the best criterion for difficulty. Mean time per problem was $7.7 \mathrm{~min}$, $18.4 \mathrm{~min}$, , and 29.2 min. for Tasks 1 through 3 , respectively ( $\mathrm{F}=$ $76.66 ; \mathrm{df}=2,30 ; \mathrm{p}<.001)$. The relationship between these means and the Difficulty scale values is very nearly linear, thus providing further evidence regarding the validity of the scale values. Differences between time scores for different feedback conditions were not statistically reliable, although less time was required by feedback groups than by the controls. The failure to find significant differences may be due in part to the fact that 21 of the 27 groups used the entire 30-minute period on Task 3 .

The basic performance score for Task 1 was the rank order correlation between the group's ranking of the cities and their true populations 
No Feedback

Task 1 (City Ranking)

Task 2 (Work Team)

Task 3 (Dormitory)
Overt Feedback

.83
3.65
1.11

Covert Feedback

.88

3.39

2.44 as given by the 1960 census. The score for Task 2 was the reduction in time required for the team to complete its assigned task; since the old time was 15 min. per unit and the shortest time possible was 10 min., per unit, scores ranged from 0 to 5 . Task 3 required answers to four questions; the score was the number of questions answered correctly. Mean performance scores are given in Table 1. Performance scores were higher with satisfaction feedback than with no feedback, and higher on Tasks 1 and 3 with covert than with overt feedback. Differences were significant only for Task $3(p<.05)$.

There were no statistically reliable differences among conditions in member satisfaction as indicated by ratings of overall satisfaction or by number of lights turned on during problemsolving interaction. However, the average correlation between ratings and number of lights was .31 in the overt feedback condition and .50 in the covert feedback condition, suggesting that satisfaction feedback was more valid in the covert than in the overt condition. The range of indicated satisfaction (by lights) was significantly less $(p<.01)$ in the overt $\left(\right.$ Mean $\left.={ }^{\circ} 1.9\right)$ than in the covert situation $($ Mean $=2.9)$.

\section{Discussion}

When group members are unaware of the feelings of the others in the group, it is likely that a decision will be accepted that is unsatisfactory to many members. When members are given an opportunity to express their satisfaction (or lack of it) directly, such premature decisions can be avoided. Minority group members and members with less aggressive interpersonal habits are more likely to be given a voice in the decision, new ideas and information can be brought to bear, etc., thus improving the decision.

The degree to which this improves the decision may be expected to vary with members' willingness to signal their true feelings. In the overt condition, members undoubtedly are in- hibited by the public nature of their signals, and so conform to the group's norm. This is indicated by the relatively low correlation between lights and private ratings, and by the decreased range of signalled satisfaction within groups. S's signals are therefore relatively invalid indicators of satisfaction, and hence are less effective in improving group performance.

\section{Summary}

Twenty-seven five-person groups attempted to solve three problems varying in difficulty. Three satisfaction feedback conditions were investigated: no feedback, overt feedback, and covert feedback. In the overt condition, Ss indicated their satisfaction publicly during the problemsolving process, whereas in the covert condition satisfaction was indicated anonymously. The results showed that with the more difficult task, group performance improved in the order no feedback, overt feedback, covert feedback. The correlation between indicated satisfaction and private ratings of satisfaction was greater in the covert than in the overt condition, and the range of indicated satisfaction was greater among members of the covert than of the overt groups. It is suggested that valid communication of satisfaction leads to more general use of members' abilities, and hence improves performance.

\section{References}

GAIER, E. L. and BASS, B. M. Effects of city familiarity on size estimation. Tech. Note 1, Contract N7 ONR 35609, Louisiana State University, Baton Rouge, November, 1955.

KRECH, D., CRUTCHFIELD, R. S. and BALLACHEY, E. L. Individual in society. New York: McGrawHill, 1962.

MAIER, N. R. F. An experimental test of the effect of training on discussion leadership. Hum. Rel., 1953, 6, 161-173.

SHAW, M. E. Scaling group tasks: A method for dimensional analysis. Tech. Report No. 1, Contract NR 170-266, Nonr - 580(11), University of Florida, Gainesville, July, 1963 . 